\title{
Kernos
}

Revue internationale et pluridisciplinaire de religion grecque antique

5 | 1992

Varia

\section{Jean WINAND, Les Hiérothytes. Recherche institutionnelle}

\section{Bruno Rochette}

\section{OpenEdition \\ Journals}

\section{Édition électronique}

URL : http://journals.openedition.org/kernos/1081

DOI : 10.4000/kernos. 1081

ISSN : 2034-7871

\section{Éditeur}

Centre international d'étude de la religion grecque antique

\section{Édition imprimée}

Date de publication : 1 janvier 1992

ISSN : 0776-3824

\section{Référence électronique}

Bruno Rochette, « Jean winand, Les Hiérothytes. Recherche institutionnelle », Kernos [En ligne], 5| 1992, mis en ligne le 16 juin 2011, consulté le 24 septembre 2020. URL : http://journals.openedition.org/ kernos/1081 ; DOI : https://doi.org/10.4000/kernos.1081 
nie des Pisistratides" et "Clisthène" constituent les cinq parties examinant l'histoire athénienne et sont suivies d'une sixième qui, elle, présente un grand intérêt notamment pour les historiens de la religion : "Les familles nobles» (p. 191-209). Cette partie réunit les sources anciennes (littéraires et épigraphiques) les plus importantes pour déterminer le rôle, dans la vie sociale, politique et religieuse d'Athènes, des puissants clans familiaux. Les Philaidai et les Alkmeonidai y occupent la plus grande place (p. 195-206), cependant que l'on notera avec regret - l'absence de clans aussi importants que les Kerykai, les Lykomidai, etc. L'ouvrage s'achève par de brèves notices sur les auteurs anciens dont il a été question (p. 210-211), un index des sources littéraires et épigraphiques traduites (p. 212-215), et un index des noms et des sujets (p. 216-226).

Ioannis LOUCAS

Jean WINAND, Les Hiérothytes. Recherche institutionnelle, Bruxelles, Palais des Académies, 1990, 1 vol. 16 x 23,5 cm, 230 p. (Académie Royale de Belgique. Mémoires de la Classe des Lettres. Coll. in $-8^{\circ}-2 e$ série, $T$. LXVIII - Fascicule 4).

On connaît la place prépondérante qu'occupait le sacrifice dans la religion grecque et l'on sait quel prestige était dévolu par la cité aux desservants du culte chargés d'en assurer le bon déroulement. Attestée presque exclusivement pär des inscriptions, la fonction de hiérothyte est mal connue tant sa nature apparaît différente selon les régions et les époques. Seule une étude reprenant le dossier $a b$ ovo pouvait contribuer à mieux faire connaître cette fonction religieuse. Après avoir étudié l'évolution sémantique de la terminologie s'y rapportant, J. Winand constitue le dossier épigraphique en suivant un plan géographique : Rhodes, le Péloponnèse, Cyrène, la Sicile, voilà les principales étapes de son enquête. Grâce à ce corpus qui compte environ 130 inscriptions, il parvient à établir plusieurs conclusions éclairantes, malgré le caractère répétitif et formulaire de la plupart des textes étudiés.

Attestés seulement à partir de la fin du Ve siècle, les hiérothytes occupent une fonction institutionnelle bien définie, dont l'origine remonte très probablement plus haut que les textes qui attestent son existence. Institution propre aux peuples du nord-ouest de la Grèce et aux Doriens, cette fonction semble avoir connu une fortune diverse selon les cités où elle fut en usage. Ici, les hiérothytes sont des personnages de rang subalterne, groupés au sein d'un collège, desservants du culte de divinités trop secondaires pour que la cité leur attribue un personnel propre. Là, en revanche, ces ministres du culte apparaissent comme des personnalités de premier rang, attachés au culte d'une grande divinité, le plus souvent la divinité tutélaire de la cité. Cette double nature de la 
magistrature amène l'A. à une conclusion ultime : ne serait-il pas possible de dresser un vocabulaire institutionnel de la Grèce qui tînt compte d'une répartition ethnique? Pour alléchante qu'elle soit, une telle piste de recherche ne pourra être exploitée que lorsque l'on disposera, pour chaque magistrature particulière, de travaux préliminaires du type de celui de J. Winand.

Prudence, fermeté, minutie : telles sont les qualités essentielles de ce travail qui, en étudiant une fonction précise, met bien en lumière "l'extrême morcellement et l'infinie variété du peuplement grec».

Bruno ROCHETTE (Liège)

Evhemeri Messenii Reliquae edidit Marcus WINIARCZYK, StuttgartLeipzig, Teubner, 1991, 1 vol., 14 × $20 \mathrm{~cm}$, XXXVII+76 p. (Bibliotheca Scriptorum Graecorum et Romanorum Teubneriana).

Auteur d'un curieux ouvrage intitulé L'inscription sacrée, Evhémère de Messine, qui voyait dans certains dieux des hommes divinisés pour leurs bienfaits, marque l'aboutissement d'un long effort d'explication rationnelle des mythes inaugurée par Philon d'Alexandrie et Plutarque. De cette œuvre intéressante, il ne reste, hélas, que quelques fragments que G. Némethy réunit pour la première fois voici un peu plus d'un siècle. Malgré tout le soin que le savant avait apporté à la constitution de son recueil, beaucoup de témoignages lui avaient échappé. Après F. Jacoby qui, dans sa grande édition des fragments d'historiens grecs, présente un choix de textes d'Évhémère, G. Vallauri donna, en 1956, une nouvelle édition des fragmenta et des testimonia, incomplète et surtout trop peu critique. Une remise à jour de ce travail s'avérait donc nécessaire. M. Winiarczyk s'est acquitté de cette tâche ingrate avec beaucoup de bonheur. Non content de présenter un relevé exhaustif des testimonia, le philologue polonais a doté son édition de notes critiques très étoffées présentant toutes les variantes textuelles, sans négliger le moindre détail. En outre, le travail comporte une bibliographie très complète et trois indices. Autant dire que cette excellente édition constituera désormais un outil de référence très précieux.

Bruno ROCHETTE (Liège) 